\title{
AN ATTEMPT OF EXPLANATORY CLASSIFICATION OF HUMAN DEVELOPMENTAL STAGES ${ }^{*}$
}

\section{Abstract}

In recent decades, interest in stages of human development sufficiently decreased. The existing stage theories were hardly criticised for methodological issues, insufficient empirical validity, but rare attempts have been made to solve these issues. As a result, contemporary developmental psychology is constructed on the basis of worldly division of ages (infancy, childhood, adolescence, etc.), but not a scientific classification. We offer an explanatory life-span developmental theory based on the functional approach. According to this theory, the function of each developmental stage is to achieve a specific goal by solving a certain developmental problem through a special developmental program. There are four developmental problems and, accordingly, four stages identified. The first problem/stage is the formation of the subject of species activity (0-7 years); the second stage is aimed at developing the subject of sexual activity (8-20, 22 years). During the third stage, a subject of family and work activity forms (20,22-40, 45 years), and the meaning of the last stage is self-exhaustion (from age 40, 45 until the end of life).

Keywords: principles of age classification, functional approach, developmental problems, developmental stages.

\section{Introduction}

Interest in stages of human development sufficiently decreased in recent decades (Bonder \& Dal, 2009), instead "... the diversity of person and context has moved into the foreground of the analysis of human development" (Lerner, 2006, p. 7). According to Arnett \& Tanner (2009), the stage theories are alternated with "life span" and "life course" metatheories, which emphasise general principles of development (such as plasticity, multi-directionality of development or human agency in development) instead of stages. This is a dichotomy-based approach, which, according to W. Overton, has never been

\footnotetext{
${ }^{*}$ This article was one of the last works during Professor Samvel Khudoyan's lifetime, which he did not manage to publish during his lifetime.
} 
successful; it “... elevates one concept of the pair to a privileged position, builds a research program on this concept, and then strives to demonstrate observationally that the non-privileged concept can be denied or marginalised" (Overton, 2006, p. 18). This approach has been rightly criticised by J. Arnett and J.Tanner: "Avoiding stages means ignoring the fascinating and important question of what qualitative changes in development may take place from one age period to the next" (Arnett \& Tanner, 2009, p. 26). Moreover, it is impossible to understand any developmental process ignoring what stages it passes and what are the qualitative differences of each stage. As van Haaften A. W (1997). mentioned: "... The notion of stages is conceptually bound up with the notion of development” (p. 16). He defines development as “...a process of change resulting in one or more qualitatively different stages for which prior stages are necessary conditions within developmental patterns" (p. 28). From this position, the issue of developmental stages cannot be outdated or rejected, and it is an actual and one of the most important problems of developmental psychology. At the same time, the methodology of existing stage theories has serious issues and has been repeatedly criticised. Vygotsky was one of the first who criticised the stage theories of his time for ignoring the development of the whole person and constructing the stages based on personality's subsystems (such as sexuality, intellect, etc.), for descriptiveness and abstraction from essential processes of development (Vygotsky, 1934/1998). Today the stage theories are also criticised for insufficient empirical validity (De Mul \& Korthals, 1997), ignorance of cultural and individual differences, fixed chronology (Pelaez et al., 2008). This criticism, for the most part, is justified, and the methodology of stage theories needs serious revision. First of all, developmental psychology must try to understand the development of the whole person (as Vygotsky states), the general and universal line of normative changes, due to which the ontogenesis of humans (even animals) is so alike. The appearance of the same anatomic-physiological, psychological and behavioural changes during the same age periods of human development indicate the existence of a universal bio-sociopsychological program that determines the stages of development. These normative changes of development are described in the textbooks of developmental psychology in an age classification that comes from ancient times and is based on the folk perception of age periods (newborn, childhood, adulthood, etc.). This stage model reflects the development of the whole person, but it only describes but not explains the normative changes. Therefore, the next task of a stage-by-stage approach is to build an explanatory age classification, which can explain the meaning of stages and the changes during the age periods. 
S. Rosova (1986) divided the classifications into descriptive and essential types. However, she considered that the essential classifications are those that explain the classified objects. The explanation in essential classifications can be causal (the objects are classified by their causal relations) or genetic (the objects are classified based on their formation and development). From this position, most of the well-known developmental stage theories are not explanatory classifications because they describe but not explain the developmental stages. Hence, only a few theories attempted to explain the developmental stages. One of them was the periodisation suggested by G. Stanley Hall, explaining ontogenetic stages based on the recapitulation theory (as cited in Thompson et al., 2012). It is a genetic classification because it attempted to explain the origin of the developmental stages (ontogenetic stages recapitulate the phylogenetic stages of development). A causal explanatory stage theory was suggested by $A$. $V$. Petrovsky (1987). He classified the ages based on educational stages (preschool age, primary school age, secondary school age, etc.) and emphasised that "...just because society creates schools the school-age as a stage of personality development appears" (Petrovsky, 1987, p. 53).

My research (2010) showed that it is possible to explain and classify the stages of human development based on a functional approach (functional explanatory periodisation) and apply objective and clear criteria to determine the developmental stages. In the next sections, I will attempt to present this theory of age periodisation.

\section{Functional approach and its application to age periodisation}

Functionalism has long traditions in developmental psychology (Dunham \& Bengtson, 1986). As it is known, it studies the functions of developmental phenomena and attempts to explain the functional meaning of ontogenetic developmental processes. Based on this approach, I suppose that each developmental stage has a special function. The meaning of the latter is to achieve a specific goal by solving a certain developmental problem through a special bio-socio-psychological program. It means that this theory explains the developmental stages teleonomically, in terms of their purposefulness, goaldirectedness and, on the other hand, describes human development as a process directed to the solution of specific developmental problems. Within the suggested theory, the terms "function of development", "developmental goal", and "developmental problem" supplement and explain each other. The function of the development is explained by the goal - the final result, that must be achieved during the developmental stage. The developmental problem reflects the way of achieving the goal. In a certain sense, these 
terms can be viewed as synonyms because their content in this theory is nearly the same. For example, within this theory, the function of the adolescent period is considered the formation of sexual activity subject, but it is also the goal of this developmental stage. The developmental problem, solved during this stage, is the same - the formation of sexual activity subject through the genetic, psychological, and social development programs and processes. However, these three terms describe different aspects of development, i.e. the function of development, its outcome, and the way of achieving the goal (i.e. problemsolving). Hence, apart from the functional approach, this theory is also based on teleonomic (Mayr, 1988) and the so-called problem (Holmes, 1958) approaches. According to Mayr (1988, p. 44), the teleonomic or goal-directed processes are common in nature, and the ontogeny is one of such processes. To describe the teleonomy in development W. F. Overton and U. Muller (2012, p. 23) used the terms "directionality", "orientation towards a goal or end state", and "Objective teleology". The objective teleonomic processes of ontogenetic development are based on "biological and social goals" which were formed during the biological evolution and history of society (Khudoyan, 2010). At the same time, one of the specific characteristics of human development is subjective goal-directedness, intentional self-development (Brandstädter, 2006) - the individuals organise their own development through setting conscious developmental goals and achieving them.

In developmental psychology, R. Havighurst (1972) introduced the problem or task approach, describing human development as a process of solution of multiple, agerelated developmental tasks such as learning to walk or achieving personal independence. My approach differs from this theory. I explain the developmental stage as a process of a step-by-step solution to only one problem. These steps can be interpreted as developmental tasks, but I prefer the term "neoformations"(Vygotsky, 1934/1998)* because the steps can also be biological changes, which cannot be viewed as tasks. In my opinion, the difference between developmental "tasks" and "problems" is that the problem relates to the result, but the tasks are separate steps in the process of solving the developmental problem. I believe that the appearance of specific biological, psychological, and social age-related neoformations are not random and independent of each other; each of them is a step in the process of solving the developmental problem. I also consider that each developmental stage has its specific motivational - energetic

\footnotetext{
* The concept of age-related "neoformations" was suggested by L. S. Vygotsky. The neoformations are the features, which appear for the first time in a certain age.
} 
base - the basic need, or drive, which stimulates the developmental processes. For example, the motivational basis of the adolescent period is the sexual drive (Khudoyan, 2010).

The developmental problem (goal) and the function of the developmental stage can be identified and defined by analysing the characteristics of age-related essential neoformations, their content, and sequences. By the term "essential neoformations," I refer to the developmental changes, which are related to the main direction of ontogenetic development in each stage. However, apart from the main direction, the development has its branches (Miklin \& Podolski, 1980). The main direction concerns the development of the personality as a whole, and the branches of the main direction show the development of subsystems of personality (development of intelligence, emotional sphere, and others). In my opinion, the main direction is reflected in the biological, psychological, and social levels of human development. It means that the neoformations of these three subsystems of personality have the same nature and content at a certain developmental stage. They are aimed at achieving the same goal. For example, in the adolescent period, the appearance of secondary sex characteristics, the actualisation of sexual drive, or learning of gender role behaviour show that the main direction of this period is the formation of sexual activity subject. From this viewpoint, the essence and the meaning of human ontogenetic stages cannot be understood on the basis of developmental characteristics of only one subsystem of personality (biological, psychological or social). The changes in all three spheres must be viewed in unity. Another characteristic of this stage theory is the attempt to define the beginning and the end of developmental stages based on objective criteria - neoformations. The end of the previous and the beginning of the new developmental stage are calculated based on the changes in the content of neoformations and the appearance of the first neoformations aimed to solve the new developmental problem. For example, at about 7-8 years of age, all human speciesspecific characteristics are already formed. No other such characteristics appear after this age. However, after 9-10 years of age, a new type of neoformations - secondary sex characteristics begin to appear. Based on these obvious facts, one may conclude that the direction of development has changed, and a new stage begins.

According to this theory, one of the specific features of human development is that the developmental process occurs in two essentially different forms - spontaneous and conscious. Biological and social programs determine spontaneous development. At this level, the developmental problem is not urgent for individuals, and they are not clearly aware of it. They do not perform a purposeful activity in order to solve a certain 
developmental problem because they and their social environment do not perceive themselves as subjects of such an activity. For example, until adolescence, the children do not perceive themselves as subjects of sexual activity and do not perform a purposeful activity in this sphere. However, at a certain period of each developmental stage, the person becomes aware of the developmental problem, understands the direction of his/her development, and perceives himself/herself as a subject of this process. From this period, the developmental process transforms into conscious, purposeful activity.

At each developmental stage, it is possible to identify the periods when spontaneous development transforms into a purposeful, conscious form of development. These periods (ages 2-3, 12-15, 25-33, and 65-75) are considered critical and are accompanied by a reorganization of self-consciousness (Khudoyan, 2010). From this perspective, each developmental stage can be divided into two periods: a period of spontaneous development and a period of conscious development.

\section{Functional stages of human development}

Based on the analysis of the functional significance of biological, psychological, and social neoformations which appear during major cycles of human development childhood, adolescence, adulthood, old age, was identified four developmental problems (goals) and, accordingly, four functional stages, directed to their solution. Analysis of the main neoformations of the embryonic period and childhood (up to 7, 8 years) revealed that the first developmental stage is aimed at the formation of species activity subject (human being). The second developmental stage is aimed at the formation of gender/sexual activity subject (8, 9 to 18, 20 years). The third developmental stage (20 to 40,45 years) is aimed at the formation of social activity subject (the subject of family and occupational activities). The last developmental stage is defined as self-realisation or self- exhaustion (from the age of 45 years until the end of life).

\section{Stage of species activity subject (human being) formation}

As it was mentioned above, the main neoformations, which appear during the embryonic period and childhood, are biological, psychological, behavioural, and social human-specific traits and, therefore, it can be concluded that the function of this developmental stage is the formation of a human being. In my opinion, the motivational basis of this stage is the need to become a representative of his own species (human being).

This stage has two periods - the biological and the psychosocial species-specific 
features formation periods (Khudoyan, 2010). The first is the embryonic period, during which the embryo becomes a human being biologically and obviously, after the birth, no other human-specific biological traits appear. This process is based on specific biological laws. According to one of them: "...an embryo first reproduces the characteristics of phylum in a whole, then the traits of class, order... from more general forms less general ... until the formation of most special traits inherent to representatives of appropriate species" (Arshavsky, 1982, p. 45).

During the next period of this stage, right after birth, the process of psychological, behavioural, and social species-specific traits formation starts. It is already a fact that during the neonatal period, infants display particular sensitivity to human faces (Johnson et al., 1991), voices (Ecklund-Flores et al.. 1996) and at the end of the first month, the newborns start reacting to other human beings with specific emotional responses (Buhler, 1935). The most reasonable explanation for these phenomena is that the newborn, due to certain genetic mechanisms, begins to recognise his/her species and accepts it. In other words, it is a specific process of imprinting.

During the first years of life, children acquire one of the most important humanspecific traits - speech, due to which many other important human characteristics, such as consciousness, verbal thinking, begins to develop. In early childhood, another human trait - bipedalism forms. Furthermore, at nearly 2-3 years of age, self-consciousness appears (Vygotsky, 1934/1998; Rochat, 2003). To become self-conscious means not only to differentiate the self from non-self but also to categorise the self into a certain category - human, girl/boy, spouse, parent, etc. My earlier research has shown (Khudoyan, 2010) that children of this age become aware of themselves as human beings and identify themselves as humans (specific self-consciousness). Some facts indicate that the roots of the specific self-consciousness date back to the primaeval times. For example, based on ethnonymic analysis A. Spirkin (1960) concluded that many primitive peoples differentiate their ethnic group from other creatures by categorising themselves as human beings. He wrote:

«... In the languages of many ethnic groups (Kurnai, Papuans, Melanesians, Botokudes, Nivkhs, Chukchi, etc.), the meaning of self-designations is "Human" or "Humans." The coincidence of a certain group's name with the word "Human being" could have arisen only in the ancient past of humanity. This indicates that the certain group as a whole became aware of itself as human beings, perceiving other groups as something else, maybe a sort of animals...» (Spirkin, 1960, p. 193).

Sprikin also stated that the facts of totemism indicate that the people of early 
patrimonial society did not separate themselves from nature; they felt their community with animals and even plants (Spirkin, 1960, p. 191-192).

The image of a human-animal hybrid and the idea of the metamorphosis of human beings into animals (the archetypes of the Sphinx, werewolf) is reflected in folklore and in the art of many people's early histories. These facts also are supporting the hypothesis that historically, the primary self-awareness of human beings was specific, and there was a period of specific uncertainty in the self-consciousness of primaeval man. Some facts indicate that nearly at 2-3 years, there is a period of species uncertainty also in the child's self-consciousness. For example, studies of preschoolers' dreams show that the images of animals prevail over the images of a dreamer's self or other humans (Foulkes, 1982). The human images in dreams start to increase from middle childhood (Helminen \& Punamäki, 2008). The research also showed that three years old children could identify themselves with animals, but later this phenomenon disappears (Clark \& Clark, 1939). As it is well known, toddlers and preschoolers identify themselves easily with animals in their games. According to B. White (1990), children whose development lag behind their peers like to play the roles of animals in games, whereas the children with normal development prefer the adult's roles. The anthropomorphic and animistic thought of preschoolers also indicates that their species self is not clearly differentiated; they feel likeness to animals. For example, for children of this age, it is not unusual that in fairy tales, cartoons, or films, animals think, speak, and act like humans.

The species uncertainty and the process of species self-identification of early preschoolers have also projected in their drawings. Children begin to draw around the age of three, and their first spontaneous drawings (a circle with two vertical lines) are humans (Lowenfeld \& Brittain, 1964). Besides humans, preschoolers like to draw animals (Boldyreva, 1974).

The hypothesis that the self-consciousness at this age is specific is also supported by some psychopathological facts concerning disturbances of self-consciousness and self - identification before the adolescent period. For example, children with pediatric schizophrenia can have species metamorphosis delusion (after the adolescent period, this syndrome is extremely rare): they can believe that they are animals, or plants, or even inanimate beings (Sukhareva, 1974). Children with such problems can deny their belonging to humans, refuse to move in a bipedal way, or speak, and their first drawings are animals instead of humans. They feel discomfort in communicating with humans and like to interact with non-humans (Sukhareva, 1974).

After the awakening of self-consciousness, the process of developmental problem 
solution achieves a conscious level. The children begin to investigate and imitate the adults and their behaviour (for example, by playing the roles of adults in the games) and try to assert themselves as full-fledged humans. They like to declare that they are big boys/girls, not babies. My previous research showed that for children, the word "big" means not big physically or in other aspects but a full-fledged human being, like adults (Khudoyan, 2010). This indicates that children of this age doubt that they are full-fledged humans.

The last human-specific neoformations of the first developmental stage can be considered morality, concrete operational thought, as well as the abilities to read, write, and calculate.

In suggested periodisation, the stage of human-specific features formation is completed around the age of 7-8 years, and no other species-specific neo-formations appear after this age.

\section{Stage of gender/sexual activity subject formation}

The function of the second developmental stage and the problem, which solves during this stage, is the formation of biologically, psychologically, and socially grown, mature male and female (ages 9 -20). All main neoformations of this stage are regarded to this sphere and the drive (need), which stimulates the developmental stage, in my opinion, is the sexual drive. Traditionally this stage is divided into phases of puberty (period of biological changes) and adolescence (period of psychosocial changes) and begins nearly at ages 8-9 years with well-known biological changes. In parallel with biological changes, the psychological and social neoformations appear (the sexual drive and feelings, intimate relationship between boys and girls, increasing interest in sex and gender roles, etc.). To me, the most significant psychological neoformations of this age are the new reconstruction of self-consciousness and the formation of gender identity. If in the previous developmental stage to "grow" means for a child to become a full-fledged human being, at this stage, as I. Kon stated: "to grow means to become a full-fledged man or woman" (Kon, 1988, p. 219). In the diffuse self-concept of children before adolescence ("I am human"), the aspect of gender is not clearly differentiated and stable; for example, many children believe that after growing up, their gender can be changed (Kohlberg, 1966). In puberty, the self-consciousness of the person reconstructs due to the fundamental changes in physical, psychological and social (changes in interrelations and attitudes towards adolescents) spheres, and the adolescents become aware of themselves and feel as male/female, as subjects of gender/sexual activity. This 
reconstruction can be characterised as a process of differentiation and integration of cognitive and sensory aspects of gender self-consciousness. The idea that in the structure of self-consciousness and identity besides the cognitive aspect (the idea of self), there is an aspect, which is not conceptual, is not based on categories we can meet in the works of different authors with different terms, such as "sensory fabric of consciousness" (Leont'ev, 1978, p. 120), pre-reflective self-consciousness or bodily self (Legrand, 2006, p. 89). I prefer to use the term sensory self-consciousness (Stanghellini, 2004, p. 151), the feeling of the self, which is normally integrated with the cognitive self and is not clearly recognised. This integrity of self-consciousness can be disturbed in some psychopathological cases. For example, in depersonalisation disorder, the cognitive aspect of the self is preserved, but the patient can declare that he/she doesn't feel himself/herself, which means that the sensory aspect of self-consciousness is disturbed. In the case of gender identity disorder, there is a conflict between the cognitive and sensory aspects of gender self-consciousness - the person knows his/her biological sex but feels himself/herself as representative of the opposite sex. A discrepancy between cognitive and sensory aspects of consciousness and self-consciousness can occur in normal cases too. For example, we can have an idea of something without having experience of that phenomenon (e.g. the idea of vacuum). I consider that such a condition occurs in the gender self-consciousness of children before adolescence - the cognitive aspect of gender self-consciousness and identity occurs before adolescence, but the sensory aspect is missing due to the lack of biological basis (level of sex hormones, secondary sex characteristics) for a sense of gender. In other words, children know their gender, but they do not feel themselves as man/woman, as subjects of sexual activity, the issues regarding the sexual sphere are irrelevant to them, and the aspect of gender in their self - concept is vague.

The gender-related changes in self-consciousness can be clearly seen in the drawings of children before and after puberty. For example, Burn (1982) reported that after the appearance of secondary sex characteristics, adolescents draw the gender differences of body and clothing in more detail; they focus too much on their body image and on the issues of masculinity/femininity in general. These facts indicate that after puberty, self-perception, body image and criteria of self-assessment are changed, and the adolescents perceive themselves not as a human in abstract as in childhood but as a woman/man and want to understand what it means to be so (Khudoyan, 2010).

After the awakening of self-consciousness, the further formation of gender activity subject becomes conscious. On the one hand, adolescents explore the traits of 
masculinity/femininity, gender values, roles, patterns, and principles of behaviour, and create images of ideal man/woman and imitate them, on the other hand, they test the gender-related behaviour and try to assert themselves as a full-fledged man/woman and develop a positive gender self-concept. Meanwhile, as research shows, uncertainty or confusion of gender identity occurs during this period (Erikson, 1993).

Overall, the process of formation of gender/sexual activity subject and the second stage of human development ends approximately at the age of 20-22. By this time, a young person reaches sexual maturity biologically, socially and psychologically, and no other neoformations concerning gender/sexual sphere appear after this age.

\section{Stage of social activity (family and occupational activities) subject formation}

According to this theory, the function of the third stage of human development (ages $20-40,45$ years), as was mentioned above, is the formation of social activity subject. By the term "social activity", I mean the two main activities of this stage - family life (marriage, parenting, and family role-taking) and occupational (pursuing a profession, building a career, occupational role-taking) activity.

Unlike previous stages, this stage does not begin with qualitative biological changes, but the body continues to grow quantitatively. However, as biological neo-formations of this stage, with some reservations, might be considered the appearance of parenting drive (Aarssen, 2007), the biological changes during pregnancy and the birth of the child. From the purely biological point of view, it can be assumed that the second and the third stages of development represent a single line and are based on the same genetic program. However, in human society, these two stages have qualitatively different sets of psychological and social neo-formations. Even in animals, these stages are based on two different and even opposite instinctive and behavioural mechanisms (sexual and parenting instincts). Therefore, I believe that after the age of 20-22, the developmental process changes its direction, and we deal with a new stage.

The psychological and social changes of the third stage of development are associated with the beginning of family life and occupational activity. The legal age of marriage in most countries is 18, and after this age, usually from 20-22 years, young people start to marry and work. The motivational basis of this stage, in my view, is the parenting drive (need for having children, the instinct of parenting), on which, most likely, is also based occupational activity. For example, many animals' behaviour, which resembles human labour (nest building or hunting for feeding the cubs), appears after the birth of the offspring (Clutton-Brock, 1991). 
During the first decade of this developmental stage (20 - 30 years), the physical and psychological systems reach their peaks (Ananev, 1980). At this age, there is a significant development also in the psychosocial sphere and in young people, as Pinyaeva and Andreev (1998, p. 5) mentioned, "....raises a sense of ownership of their lives, social responsibility for themselves, their actions and ... for others." It can be assumed that reaching the peak of mental and physical development is a genetic signal that stimulates the actualisation of parenting drive; the person feels the power, confidence, and desire to care for others.

Around the age of 30 , the third reconstruction of self-consciousness takes place (Khudoyan, 2010): young people begin to perceive and evaluate themselves as subjects of social activity - as a professional, parent, and spouse. During the second decade of this stage (30-40 years), young adults usually acquire occupational and family roles and reach a particular social and economic status.

This developmental stage ends at around 40-45, and development changes its direction, a new type of neoformations - ageing signs begin to appear.

\section{Stage of self - realisation and exhaustion}

For the last stage of human development and the second half of life (from the ages 40, 45 until the end of life), I prefer the term "self - realisation/exhaustion." If in the first half of the life (until 40 years of age) the developmental tendency is the formation, growth, and maturation of personality, in the second half, the tendency can be characterised as the realisation of inner potential, and, as a result, exhaustion of personality as a subject of gender, family, occupational activities and, finally, as a human being (the death). I consider that the second half of life's motivational basis is the need for self -exhaustion (or death drive). This need manifests itself in the desire to realise the inner potential and meaning of life, reach the main goals of life, and manage all incomplete tasks.

This stage of development also begins with physical changes. At the age of 35-40, most biological systems reach their peak of development and start to decline, signs of ageing appear. After the age of 50 , the process of sexual activity subject exhaustion starts. Sexual desire and frequency of sexual activity decrease, gender role differences become less distinct, integration and exchange of gender-related characteristics occur, sex-typing becomes more fluid (DeLamater \& Sill, 2005; DeLamater \& Moorman, 2007). This phenomenon Gutmann characterised as "normal unisex of later life" (Gutmann, 1975).

The subject of parental activity begins to exhaust when the youngest children 
start to work, leave the parental home, get married, and begin to live independently. The subjective feeling of exhaustion is often reflected in the so-called "post parental transition" (Borland, 1982). Apart from social signs of parental activity exhaustion, there are also biological markers, one of which is menopause.

Another normative life event that signals the exhaustion of social activity subject is the retirement and the end of the professional activity.

Between the ages of 60 and 70, the physical, psychological, and social changes lead to a new reconstruction of self-consciousness and identity (Khudoyan, 2010). I assume that during this period appears the self-consciousness of a mortal. Before this age, the person knows that everybody dies and he/she will die too but does not feel it. The sensory aspect of the self-consciousness of a mortal is missing (Khudoyan, 2010). During this stage, the elderly understand and feel that they really are approaching the end of life. Death becomes an actual problem, and the elderly face tough questions about how they have lived their lives and what is the meaning of life in this age, what sensations appear during death, there is life after death (Khudoyan, 2010). Based on reflections on these topics, the elderly create concepts of their new self and the remaining lifetime. These concepts can play an essential role in the ageing process and determine the type of self-exhaustion. In this regard, I distinguish two types or strategies of self-exhaustion - passive and active. In the first case, a person feels exhausted (accompanied by anxiety and depression) and resorts to maladaptive defence mechanisms - living in the past, focusing on health outcomes, neurotic or even psychotic reactions, alcohol abuse (Steffens \& McQuoid, 2005; Livingston et al., 1997). In the case of active self-exhaustion, older adults concentrate on their everyday tasks, set new goals, and achieve them (Khudoyan, 2010).

This stage is ending with complete psychological, social, and biological exhaustion of personality, i.e. the death.

\section{Conclusion}

I have tried to build a functional periodisation of human ontogeny. This periodisation has, in my view, several advantages. First, it encompasses the whole life cycle. It considers not only the psychological but also biological and social facts of development. Moreover, the age-specific biological, psychological, and social changes (neoformations) are viewed in unity in the developmental process's logical chain. It suggests clear criteria for defining the borders of developmental stages. This is an explanatory classification of ages, and it explains the developmental cycles based on their functional meaning. 


\section{References}

Aarssen, L. W. (2007). Some bold evolutionary predictions for the future of mating in humans. OIKOS: Synthesizing Ecology, 116, 1768-1778.

Ananev, B.G. (1980). Izbrannye psikhologicheskie trudy $\vee 2$ tomakh (Selected psychological works in two volumes), vol. 1, Moscow: Pedagogica.

Arnett, J. J., \& Tanner, J. L. (2009). Toward a cultural-developmental stage theory of the life course. In K. McCartney \& R. A. Weinberg (Eds.), Experience and development: A festschrift in honor of Sandra Wood Scarr. Hove UK, psychology press, pp. 17-38.

Arshavsky, I.A. (1982). Phiziologicheskie mekhanizmi i zakonomerosti individualnogo razvitiya (Physiological mechanisms and regularities of the individual development). Moscow: Nauka.

Boldyreva, S. (1974). Risunki detey doshkolnogo vozrasta bolnikh shizofreniey (Drawings of children of preschool age with schizophrenia). Moscow: Meditsina.

Bonder, B., \& Dal, B.-H. V. (2009). Functional performance in older adults. Philadelphia: F.A. Davis Co

Borland, D. C. (1982). A cohort analysis approach to the empty-nest syndrome among three ethnic groups of women: a theoretical position. Journal of Marriage and the Family, 44 (1), 117-129. doi: 10.2307/351267

Brandstädter, J. (2006). Action perspectives on human development. In W. Damon \& R. M. Lerner (Eds.), Handbook of child psychology: Vol. 1. Theoretical models of human development (6th ed., pp. 516-568). Hoboken, NJ: John Wiley \& Sons.

Buhler, C. (1935). From birth to maturity: an outline of the psychological development in Young Children. London: Routledge \& Kegan Paul.

Burns, R. B. (1982). Self-concept development and education. London: Holt, Rinehart, \& Winston.

Clark, K. B., \& Clark, M. P. (1939). The development of consciousness of self and the emergence of racial identification in Negro preschool children. Journal of Social Psychology, 10 (4), 591-599. doi: 10.1080/00224545.1939.9713394

De Mul, J \& Korthals, M. (1997). Developmental philosophy and postmodernism. In van Haaften, W., Korthals, M., \& Wren, T. (Eds.). Philosophy of development: Reconstructing the foundations of human development 
and education. Dordrecht / Boston / London: Kluwer Academic Publishers. pp. 245-260.

DeLamater, J., \& Moorman, S. (2007). Sexual behavior in later life. Journal of Aging and Health, 19 (6), 921-945. doi: 10.1177/0898264307308342.

DeLamater, J.D., \& Sill, M. (2005). Sexual desire in later life. The Journal of Sex Research, 42 (2), 138-149. doi: 10.1080/00224490509552267

Dunham, C.C., \& Bengtson, V.L. (1986). Conceptual and theoretical perspectives on generation relations. In N. Datan, A. Greene \& H. Reese (Eds.), Lifespan developmental psychology: intergenerational networks (pp. 127). Hillside, NJ: Erlbaum.

Ecklund-Flores, L. \& Turkewitz, G. (1996). Asymmetric head turning to speech and non speech in human newborns. Developmental Psychobiology, 29(3), 205-217. doi: 10.1002/(SICI)1098-2302(199604)29:3<205::AIDDEV2>3.0.CO;2-V

Erikson, E. H. (1993). Childhood and society. New York: Norton.

Foulkes, D. (1982). Children's dreams: Iongitudinal studies. New York: John Wiley and Sons.

Gutmann, D. (1975). Parenthood: A key to the comparative study of the life cycle. In N. Datan \& L. Ginsberg (Eds.), Life-span developmental psychology: normative life crisis (pp. 167-184). New York: Simon \& Schuster.

Havighurst, R. S. (1972). Developmental tasks and education. New York: David Mckey comp.

Helminen, E. \& Punamäki, R. L. (2008). Contextualised emotional images in children's dreams: Psychological adjustment in conditions of military trauma. International Journal of Behavioral Development, 32 (3), 89-99.

Holmes, B. (1958). The problem approach in comparative education: some methodological considerations. Comparative Education Review, 2 (1), 3-8.

Johnson, M. H., Dziurawiec, S., Ellis, H., \& Morton, J. (1991). Newborns' preferential tracking of face-like stimuli and its subsequent decline. Cognition, 40 (1-2), 1-19. doi:10.1016/0010-0277(91)90045-6

Khudoyan, S. S. (2010). Ontogeneticeskie perestroiki samosoznaniya i krizisi razvitiya lichnosti (The ontogenetic reorganisations self-consciousness and crises of personality development). Yerevan: Zangak-97.

Kohlberg, L. (1966). A cognitive-developmental analysis of children's sex-role concepts 
and attitudes. In Maccoby, E. E. (Ed.). The development of sex differences (pp. 82-173), Stanford, CA: Stanford University Press.

Kon, I. S. (1988). Vvedenie v seksologiiu (Introduction to sexology). Moscow: Meditsina.

Legrand, D. (2006). The bodily self: The sensorimotor roots of pre-reflective selfconsciousness. Phenomenology and the Cognitive Sciences 5 (1), 89118. doi: $10.1007 / \mathrm{s} 11097-005-9015-6$

Leont'ev, A.N. (1978). Activity, consciousness, and personality. Englewood Cliffs, New Jersey: Prentice-Hall.

Lerner, R.M. (2006). Developmental Science, Developmental Systems, and Contemporary Theories of Human Development. In W. Damon \& R.M. Lerner (Eds.). Handbook of Child Psychology, Volume One: Theoretical Models of Human Development (6th ed.), pp. 1-17. New York: John Wiley \& Sons, Inc.

Lowenfeld, V. \& Brittain, W. L. (1964). Creative and mental growth. New York: The Macmillan Co.

Mayr, E. (1988). Toward a New Philosophy of Biology: Observations of an Evolutionist. Cambridge, MA: Belknap Press.

Miklin, A. M. \& Podolski, V. A. (1980). Kategoriya razvitiya $v$ marksistskoy dialektike (Category of development in Marxist dialectics). Moscow: Mysl.

Overton, W. F. (2006). Developmental Psychology: Philosophy, Concepts, Methodology. In R. M. Lerner (Ed.). Theoretical models of human development. Volume 1 of Handbook of Child Psychology (6th ed.). Editors-in-chief: W. Damon \& R. M. Lerner. Hoboken, New York: Wiley. pp. 18-88).

Overton, W. F., \& Müller, U. (2012). Metatheories, theories, and concepts in the study of development. In R. M. Lerner, M. A. Esterbrooks, \& J. Misatry (Eds). Comprehensive handbook of psychology (pp. 19-58): Developmental psychology (Vol. 6). New York: Wiley. doi: 10.1002/9781118133880.hop206002

Pelaez M, Gewirtz J.L, Wong S.E. (2008). A critique of stage theories of human development: A pragmatic approach in social work. In: Thyer B.A, editor. Comprehensive handbook of social work and social welfare: Vol. 2: Human behavior in the social environment. New York: Wiley. pp. 503-518. doi: 10.1002/9780470373705.chsw002020

Petrovsky, A. V. (1987). Razvitie lichnosti: vozrastnaya periodizatsia (Development of personality: age periodisation). In A. V. Petrovsky (Ed.). Psikhologia 
razvivaiusheisia lichnosti (Psychology of developing personality) (pp. 38-76). Moscow: Pedagogica.

Pinyaeva, S. I. \& Andreev, I.V. (1998). Lichnostnoe i professional'noe razvitie v period zrelosti (Personal and professional development in adulthood). Voprosy psychologii (Psychology issues), 2, 3-10.

Rochat, P. (2003). Five levels of self-awareness as they unfold early in life. Consciousness and Cognition, 12 (4), 717-731. doi: 10.1016/S10538100(03)00081-3

Rozova, S. (1986). Klassifikacionnaja problema v sovremennoj nauke (The Classification problem in modern science), Novosibirsk: Nauka.

Spirkin, A. (1960). Proiskhozhdenie soznaniia (The origin of consciousness), Moscow: Gospolitizdat.

Stanghellini, G. (2004). Disembodied Spirits and Deanimated Bodies: The Psychopathology of Common Sense. Oxford: Oxford University Press.

Steffens, D. C., \& McQuoid, D. R. (2005). Impact of symptoms of generalised anxiety disorder on the course of late-life depression. American Journal of Geriatric Psychiatry, 13 (1), 40-47. doi: 10.1176/appi.ajgp.13.1.40

Sukhareva, G. E. (1974). Lektsii po psikhiatrii detskogo vozrasta (Lectures on child psychiatry). Moscow: Meditsina.

Thompson, D., Hogan, J. D., \& Clark, P. M. (2012). Developmental psychology in historical perspective. Chichester, West Sussex; Malden, MA: WileyBlackwell.

van Haaften A. W. The concept of development (1997). In Van Haaften, A.W., Korthals, Michiel, Wren, T.E. (Eds.). Philosophy of development: Reconstructing the foundations of human development and education. pp 13-29.

Vygotsky, L.S. (1934/1998). The problem of age. In R. W. Rieber (Ed.). The collected works of L. S. Vygotsky: Vol. 5. Child psychology (pp. 187-205). New York: Plenum Press.

White, B. L. (1990). The first three years of life. New York: Prentice Hall Press. 